\title{
Efficacy of the complementary therapies in the management of cancer pain in palliative care: A systematic review*
}

\author{
Luís Carlos Lopes-Júnior ${ }^{1}$ \\ (D) https://orcid.org/0000-0002-2424-6510 \\ Gabriela Sylvestre Rosa ${ }^{1}$ \\ (1D) https://orcid.org/0000-0001-5158-6206 \\ Raphael Manhães Pessanha ${ }^{1}$ \\ (1D) https://orcid.org/0000-0001-6893-0755 \\ Sara Isabel Pimentel de Carvalho Schuab ${ }^{1}$ \\ (D) https://orcid.org/0000-0002-8372-325X \\ Karolini Zuqui Nunes ${ }^{1}$ \\ (D) https://orcid.org/0000-0003-3433-4925 \\ Maria Helena Costa Amorim² \\ (D) https://orcid.org/0000-0002-4252-7092
}

\begin{abstract}
Objective: to synthesize the knowledge and to critically evaluate the evidences arising from randomized controlled trials on the efficacy of the complementary therapies in the management of cancer pain in adult patients with cancer in palliative care. Method: a systematic review guided by the Preferred Reporting Items for Systematic Reviews and MetaAnalyses. The search for articles in the MEDLINE, ISI Web of Knowledge, CENTRAL Cochrane, and PsycINFO databases, as well as the manual search, selection of studies, data extraction, and methodological assessment using the Cochrane Bias Risk tool were performed independently by two reviewers. Results: eight hundred and fifteen (815) studies were identified, six of them being selected and analyzed, of which three used massage therapy, one study used a combination of progressive muscle relaxation and guided imaging, and another two studies used acupuncture. Most of the studies had an uncertain risk of bias $(n=4 ; 67 \%)$. Conclusion: while the evidence from the studies evaluating the use of massage therapy or the use of progressive muscle relaxation and guided imaging for the management of cancer pain in these patients demonstrated significant benefits, the other two studies that evaluated the use of acupuncture as a complementary therapy showed contradictory results, therefore, needing more research studies to elucidate such findings.
\end{abstract}

Descriptors: Complementary Therapies; Adult; Cancer Pain; Palliative Care; Oncology Nursing; Evidence-Based Nursing.

\section{How to cite this article}

Lopes-Júnior LC, Rosa GS, Pessanha RM, Schuab SIPC, Nunes KZ, Amorim MHC. Efficacy of the complementary therapies in the management of cancer pain in palliative care: A systematic review. Rev. Latino-Am. Enfermagem. 2020;28:e3377. [Access f f f]; Available in: DOI: http://dx.doi.org/10.1590/1518-8345.4213.3377. month day year 


\section{Introduction}

The latest report on the global cancer burden in the world, according to the GLOBOCAN 2018 estimates, has estimated about 18.1 million new cases of cancer and 9.6 million deaths due to malignant neoplasms in $2018^{(1)}$. Reaching alarming levels, cancer is a contemporary global public health problem, being the second leading cause of mortality in several countries ${ }^{(2)}$. Estimates from the World Health Organization (WHO) indicate that, in 2030, cancer will reach approximately 27 million incident cases worldwide, 17 million deaths, and 75 million people with annual diagnosis(3). The greatest effect will be noticeable in low- and middle-income countries. For each year of the 2020-2022 triennium, in Brazil the occurrence of 625 thousand new cancer cases was estimated(4).

Cancer pain is a symptom related to multiple factors, defined as "simultaneous sensations of acute and chronic pain, of different levels of intensity, associated with the invasive spread of tumor cells in the body; a consequence of the cancer treatment, including chemotherapy, or cancer-related conditions; being generally described as imprecise, hurting, frightening or as an unbearable sensation, with episodes of intense sensations, accompanied by difficulties to sleep, irritability, depression, suffering, isolation, hopelessness, and helplessness"(5). Although the WHO Analgesic Scale has been widely used(6-7), approximately $40 \%$ to $50 \%$ of the cancer pain cases have inadequaterelief due to their multi-factorial nature ${ }^{(8)}$. There is still a shortage of effective pain management schemes for many cancer patients, especially those in palliative care ${ }^{(9-10)}$. Thus, a combination of pharmacological and non-pharmacological treatment modalities for cancer pain should be the standard care, due to the complexity of this symptom ${ }^{(10-11)}$.

Palliative care was defined in 1990 and redefined in 2002 by the WHO as an approach that improves the quality of life of patients and their families facing the problem associated with life-threatening illness, through the prevention and relief of suffering by means of early identification and impeccable assessment and treatment of pain and other physical, psychosocial, and spiritual problems ${ }^{(12)}$. Nurses play an important role in palliative care, with responsibility for providing information, counseling, and education to the patients and their families in maintaining the home/hospital dyad(13). Due to the strong bond with patients and for being at the frontline of care, they are in the best position for handling the cancer symptom clusters $^{(13-15)}$. It is highlighted that, for many cancer patients in palliative care, drug therapy is insufficient for pain relief or does not match the patient's choice ${ }^{(11)}$. Thus, it becomes essential to use complementary therapies (CTs) in addition to the conventional ones for cancer pain management ${ }^{(11,15-16)}$.

The National Center for Complementary and Alternative Medicine (NCCAM) defines Complementary Alternative Medicine as a set of practices, medical and health care systems for individuals who are not considered part of conventional medicine ${ }^{(17)}$. The CTs cover techniques aimed at prevention, promotion, treatment, and recovery, in order to integrate the physical, mental, and spiritual dimensions of the human being. There are several ways to classify these therapies. The NCCAM categorizes them mainly as: use of natural products; body and mind practices; and body-based manipulation practices $^{(17)}$. Over the past three decades, the use of CTs has increased considerably both in pediatric patients ${ }^{(18-22)}$ and in the adult population ${ }^{(23-26)}$. However, the efficacy of the CTs for cancer pain management in adults with cancer in palliative care is still a gap in the scientific literature ${ }^{(11)}$.

In this sense, this study aimed to synthesize the knowledge and to critically evaluate the evidence from randomized controlled trials on the efficacy of the complementary therapies in the management of cancer pain in adult cancer patients in palliative care.

\section{Method}

This study is a systematic review of the literature, which was guided by the Preferred Reporting Items for Systematic Reviews and Meta-Analyses (PRISMA). In order to guarantee the reliability of the data and methodological transparency, we filed the registration in the International Prospective Register of Systematic Reviews (PROSPERO/NHS) - Record Number: CRD42020156074.

To formulate the objective and the review question, the following strategy was used: PICOS $(P-$ Population or Patients; I-Intervention; C - Comparison; O - Outcomes; $S$ - Study design), where $\mathrm{P}=$ Population (adults with cancer in palliative care), I = Intervention (complementary therapies), $\mathrm{C}=$ Comparison (control group not receiving intervention or receiving standard/usual clinical care), $\mathrm{O}=$ Outcomes (reduction of cancer pain), and S = Study design (randomized controlled trials)(27). This strategy facilitated the structuring of critical reasoning on the topic and the formulation of the following question: "What is the existing scientific evidence from the randomized controlled trials on the efficacy of complementary 
therapies in the management of cancer pain in adults with cancer in palliative care?"

Primary studies were included whose design was a randomized controlled trial (RCT) conducted with adult patients ( $\geq 19$ years old), of both genders, diagnosed with any type of malignancy in palliative care; studies covering the efficacy of some complementary therapy classified by The National Center for Complementary and Alternative Medicine (National Institutes of Health, USA), which categorizes them mainly as: use of natural products; body and mind practices; and body-based manipulation practices ${ }^{(17)}$ and whose primary outcome was cancer pain. There was no restriction regarding the languages or publication year. Quasi-experimental studies, literature review studies; theses and dissertations; book chapters, clinical guidelines, technical reports and editorials were excluded. The search for the studies was carried out systematically in four electronic databases: MEDLINE - Medical Literature Analysis and Retrieval System Online (via PubMed), Cochrane Central Register of Controlled Trials (CENTRAL Cochrane), ISI Web of Knowledge via Web of Science, and PsycINFO (Psychology Information).
The search strategy of the studies was composed by a combination of controlled descriptors (indexers in the respective databases) and keywords, according to the indication offered in each electronic database. Thus, to search for articles on MEDLINE, controlled descriptors were used from the Medical Subject Headings (MeSH); and the PsycINFO Thesaurus was consulted for the PsyciNFO database. The keywords were established after a thorough reading related to the investigated topic. In order to expand the search strategy, a combination of controlled descriptors and keywords was performed using Boolean operators ${ }^{(28)}$.

The Boolean operators AND and OR were used to obtain restrictive and additive combinations, respectively. In addition, the search was carried out using identified descriptors and with a broader sense, without using the database filters to preserve significant samples and ensure less risk of losses. This strategy justifies the small number of studies selected in view of the sample obtained, added to the fact that we establish the RCT as an inclusion criteria as a design to encompass the strongest evidence for decisionmaking into clinical practice ${ }^{(28)}$. Figure 1 shows the final search strategy processed in the respective databases.

\begin{tabular}{|c|c|}
\hline Database & Search Strategy \\
\hline $\begin{array}{l}\text { MEDLINE } \\
\text { /PubMed } \\
\text { 08-30-2019 }\end{array}$ & 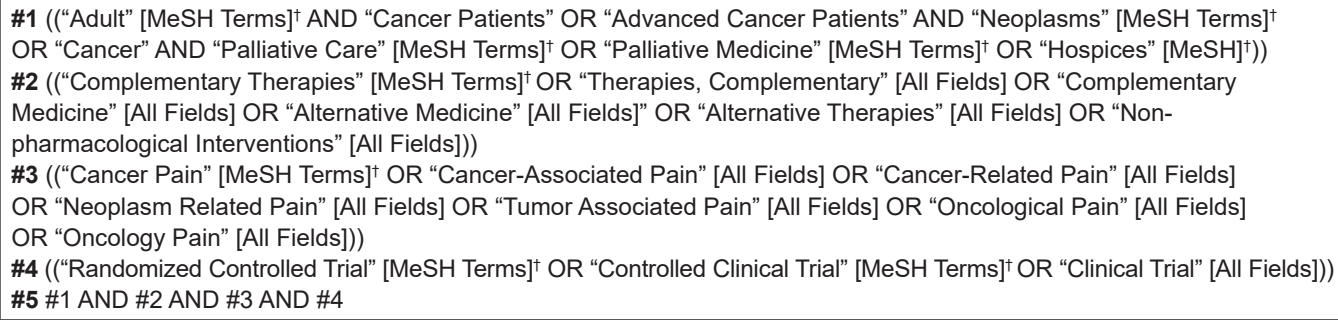 \\
\hline $\begin{array}{l}\text { CENTRAL Cochrane }{ }^{\ddagger} \\
\text { 08-30-2019 }\end{array}$ & 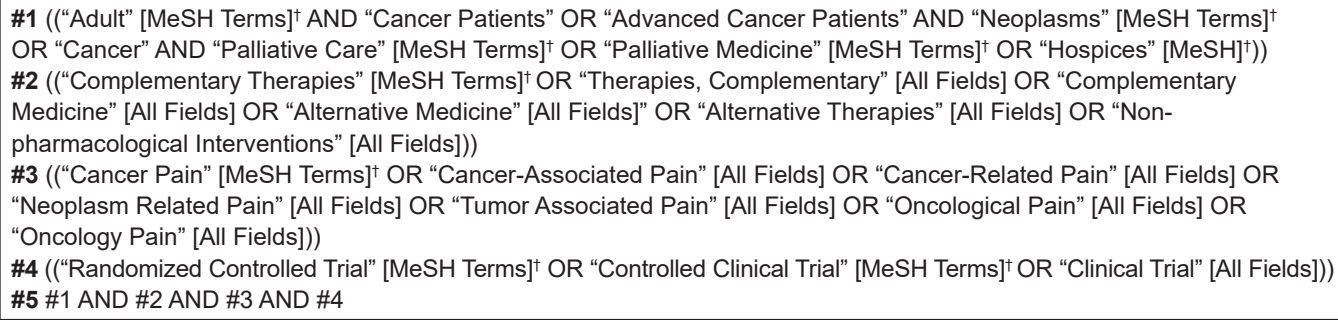 \\
\hline $\begin{array}{l}\text { ISI of Knowledge } \\
\text { of Science } \\
08-30-2019 \pi\end{array}$ & 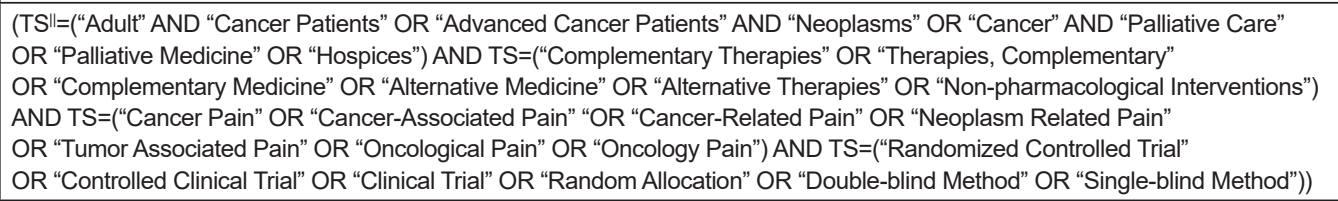 \\
\hline $\begin{array}{l}\text { PsyclNFO§ } \\
08-30-2019 \pi\end{array}$ & 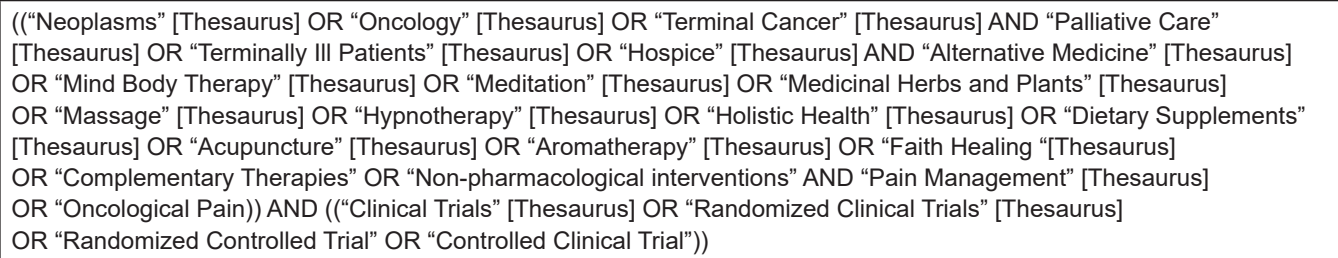 \\
\hline
\end{tabular}

${ }^{*}$ MEDLINE = Medical Literature Analysis and Retrieval System Online; ${ }^{+}$MeSH = Medical Subject Headings; ${ }^{*}$ CENTRAL $=$ Cochrane Central Register of

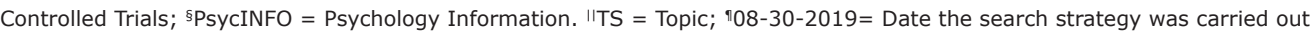

Figure 1 - Database search strategy in the MEDLINE/PubMed, CENTRAL Cochrane, ISI Web of Knowledge/Web of Science, and PsycINFO databases, on August 30 th 2019. Vitória, ES, Brazil. 2019 
It should be noted that there were no publication date or language restrictions in the search strategy held. In addition to the aforementioned electronic databases, secondary searches were carried out from other sources, such as Clinical Trial Records sites like ClinicalTrials. gov (National Institutes of Health, NIH, USA), and The Brazilian Clinical Trials Registry (via the ReBEC Platform). Moreover, the list of final references contained in the included primary studies was analyzed manually in order to find relevant studies to be added. In this stage of the review, the EndNote ${ }^{\mathrm{TM}}$ reference manager (https://www.myendnoteweb.com/) was used to store, organize, and delete duplicates, in order to ensure a systematic, comprehensive, and manageable search.

The sample was independently and blindly selected by two reviewers in August 2019. After this selection, a third reviewer was responsible for analyzing and deciding (together with the previous ones) on the inclusion or exclusion of each article, especially in relation to those containing conflicting decisions. After the selection of the third reviewer, a manual search was conducted based on the references of the selected articles.

Data were extracted based on pre-established tools ${ }^{(29-31)}$ and included four domains: I) Identification of the study, with data such as the title of the article, impact factor of the journal, country of the authors of the study, year of publication, host institution of the study (hospital; University; research facility; multicenter study or study in a single institution); conflicts of Interest; funding; II) Methodological characteristics (study design; objective of the study or research question or hypotheses); sample characteristics, for example, sample size, age, baseline characteristics for the experimental and control groups, recruitment method, drop-outs, follow-up time, statistical analysis; III) Main findings and implications for clinical practice; and IV) Conclusions.

For data extraction, two Microsoft Word ${ }^{\circledR}$ tables were created independently by two researchers to synthesize data from the included studies. After this phase, the tables were compiled into a single one to proceed with the qualitative analyses.

The evaluation of the methodological quality of the studies was defined as an essential process to establish internal validity, checking the possible biases and the reliability of the identified evidence. In this systematic review of RCT, the methodological quality of the included studies was assessed by two independent reviewers, using the Cochrane Bias Risk tool from the Handbook of the Cochrane Collaboration for Systematic Intervention Reviews, version 5.1.0 (32), which assesses the following seven domains: I) Allocation of the randomization sequence (selection bias); II) Allocation concealment (selection bias); III) Blinding of the participants and the team involved (performance bias); IV) Blinding of outcome evaluators (detection bias); V) Incomplete outcomes (attrition bias); VI) Report of selective outcome (publication bias); and VII) Other sources of bias. Based on these assessed domains, the studies are classified as low, high, or uncertain bias risk.

The studies were classified according to the risk of bias as follows: "Low" if all the main domains were classified as "low risk"; "Uncertain" if one or two main domains were classified as "uncertain risk"; and "high" if more than two main domains have been classified as "uncertain" or "high risk". When no information was available, we assign "uncertain risk"(33).

As most of the studies evaluated showed significant methodological differences, it was decided to perform a qualitative synthesis of the data in this systematic review.

\section{Results}

The searches in the four electronic databases, as well as the manual search in other sources, resulted in 815 studies. We identified 53 studies that were duplicated in the databases. After removing them using the EndNote ${ }^{\mathrm{TM}}$ reference manager, 762 studies went on to the selection process by title and abstract. At this stage, 745 studies were excluded for not meeting the pre-established inclusion criteria. The exclusion by title and abstract resulted in the selection of 17 studies that were read in full-text. After this stage for exhaustive reading of the full-text studies, another 11 studies were excluded, resulting, therefore, in six articles that were included for qualitative synthesis and analysis (Figure 2).

Regarding the characteristics of the studies, the publication date of the six articles included varied in the range from 2004 to 2019(35-40), and all were published in the English language with a randomized controlled trial design carried out in different countries.

Figure 3 chronologically synthesizes the main characteristics of the studies included in the qualitative synthesis of this systematic review. 


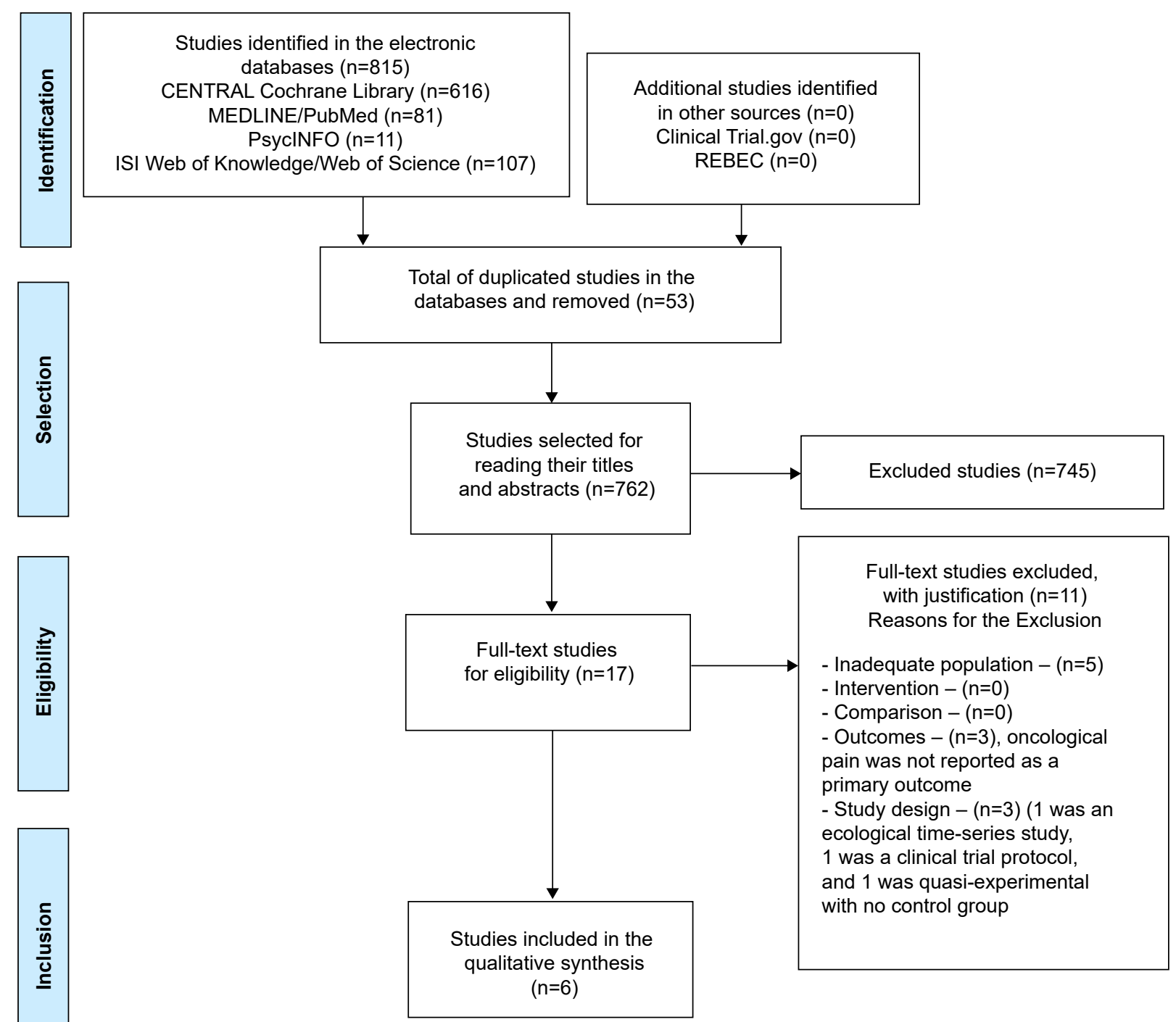

Figure 2 - PRISMA flow chart(34) for selecting the studies. Vitória, ES, Brazil. 2019 


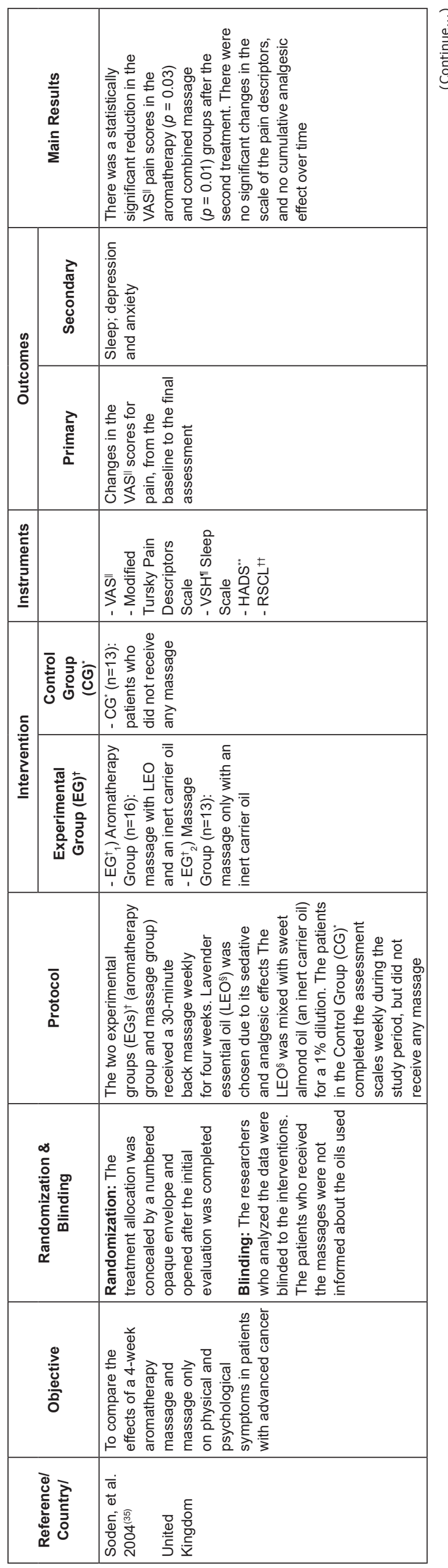




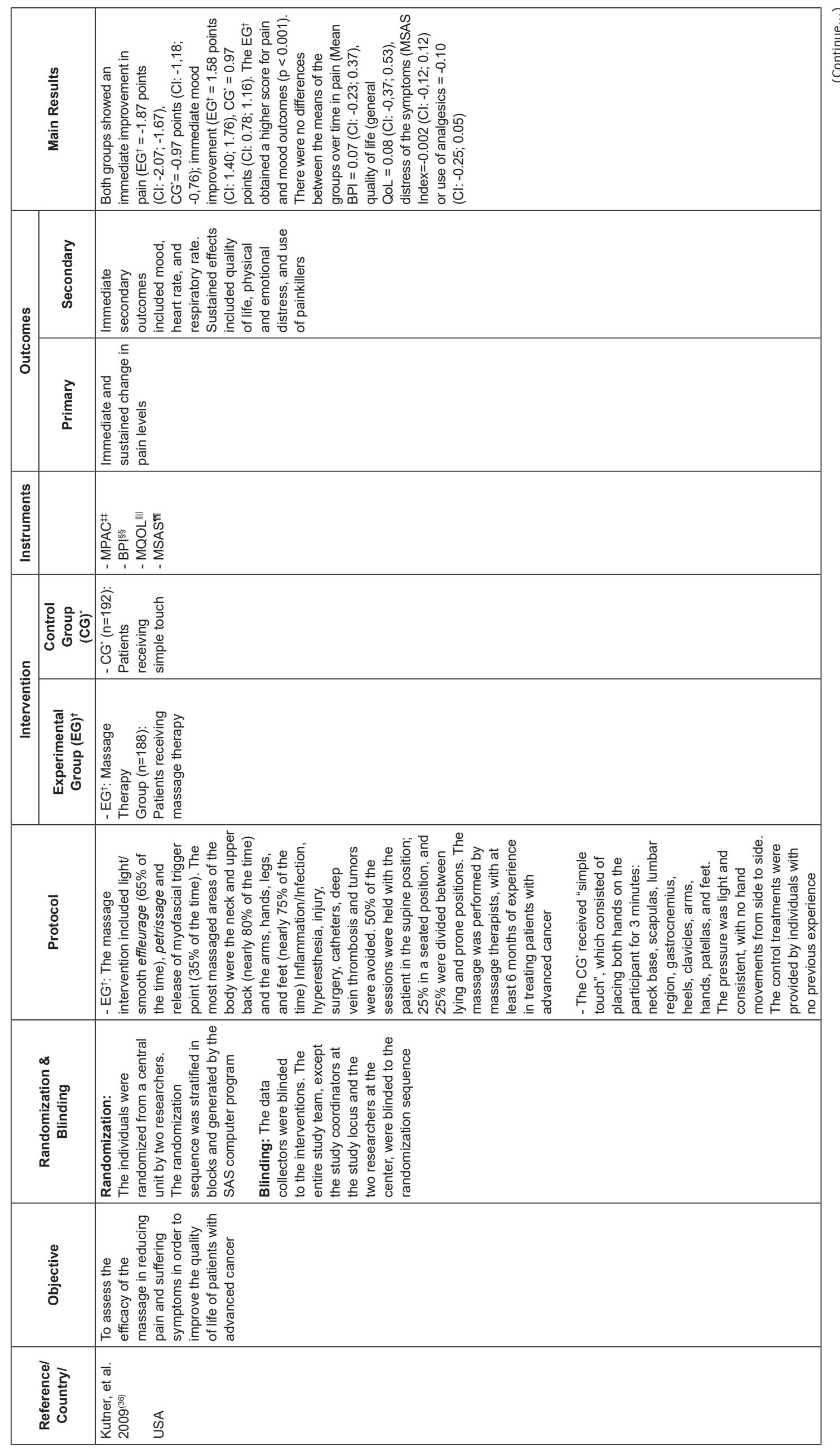




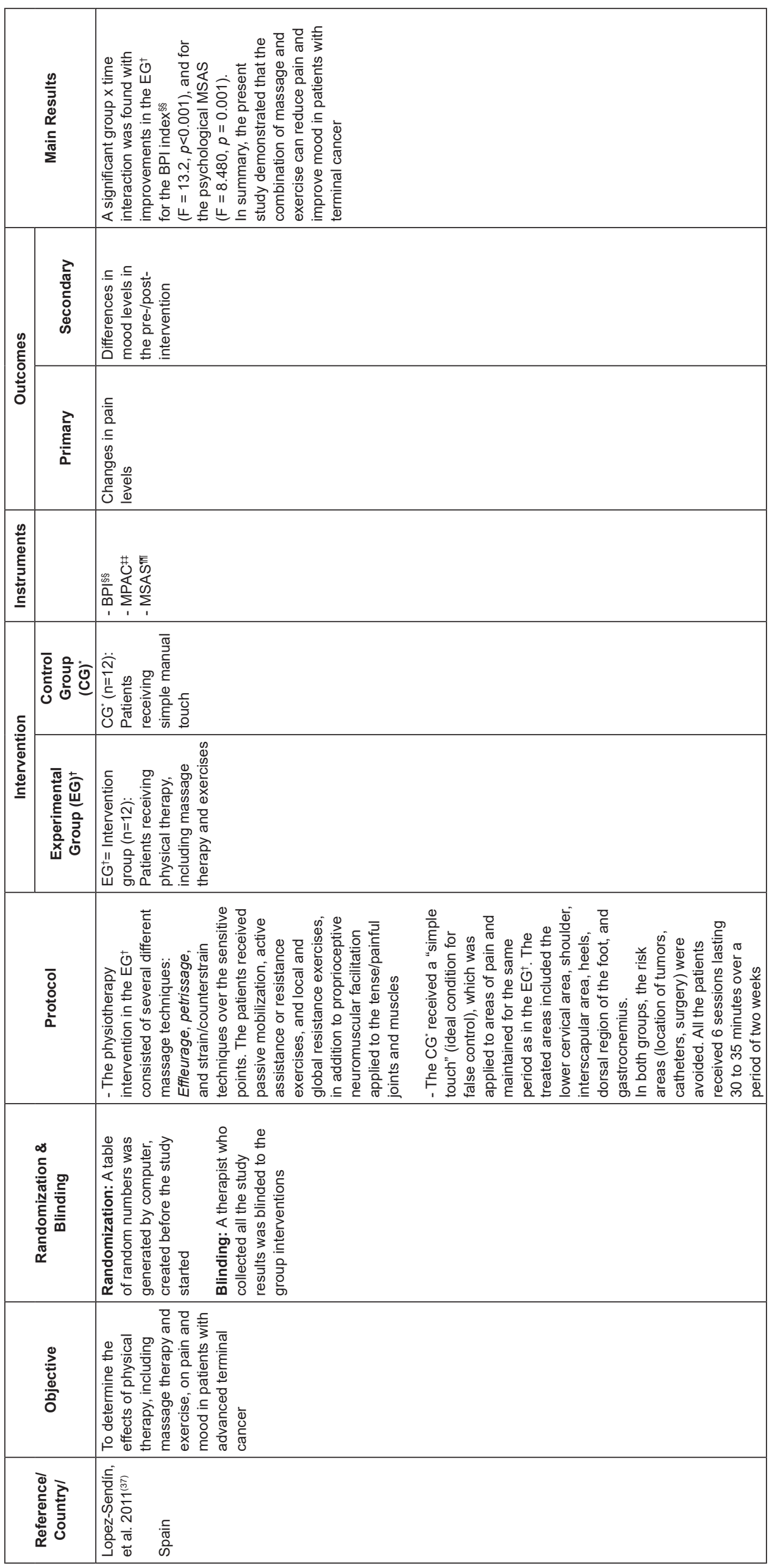




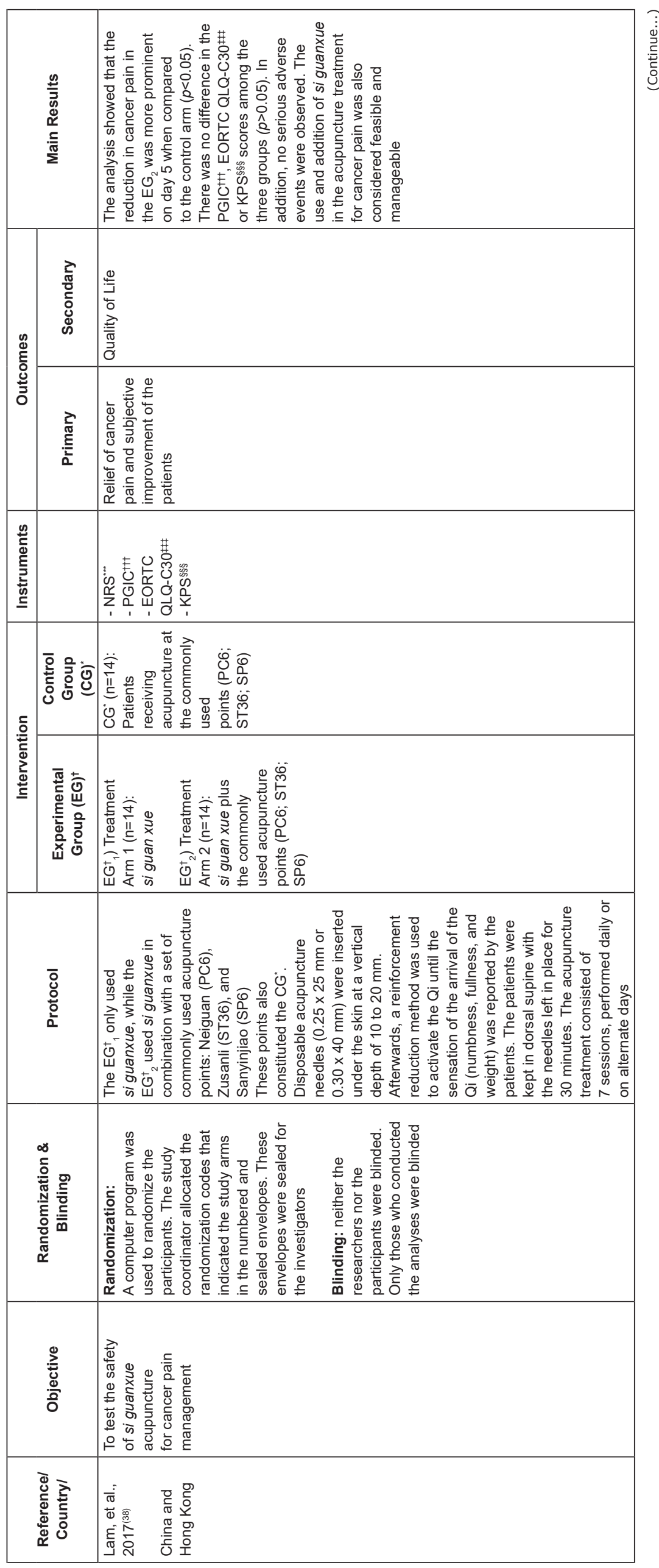




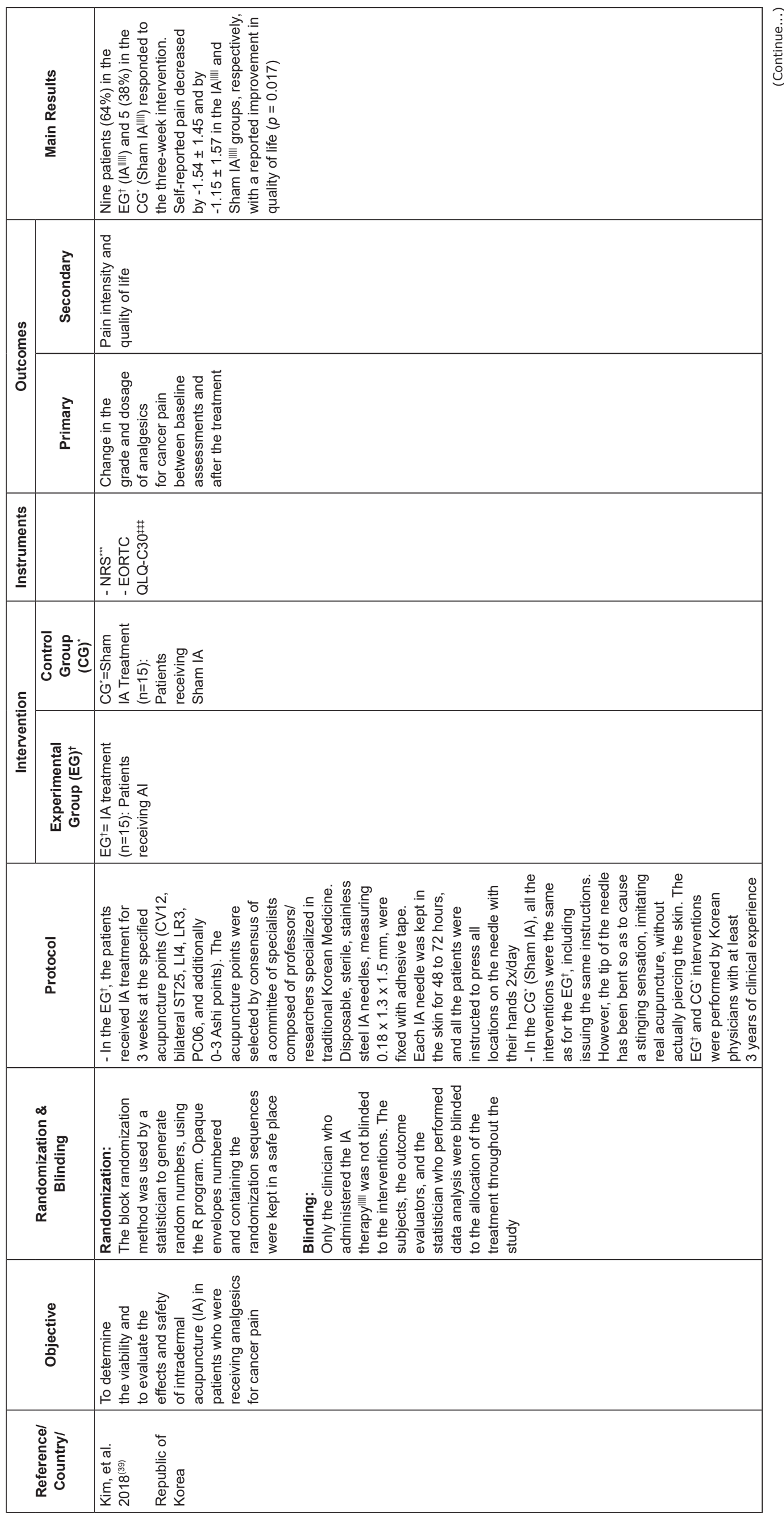




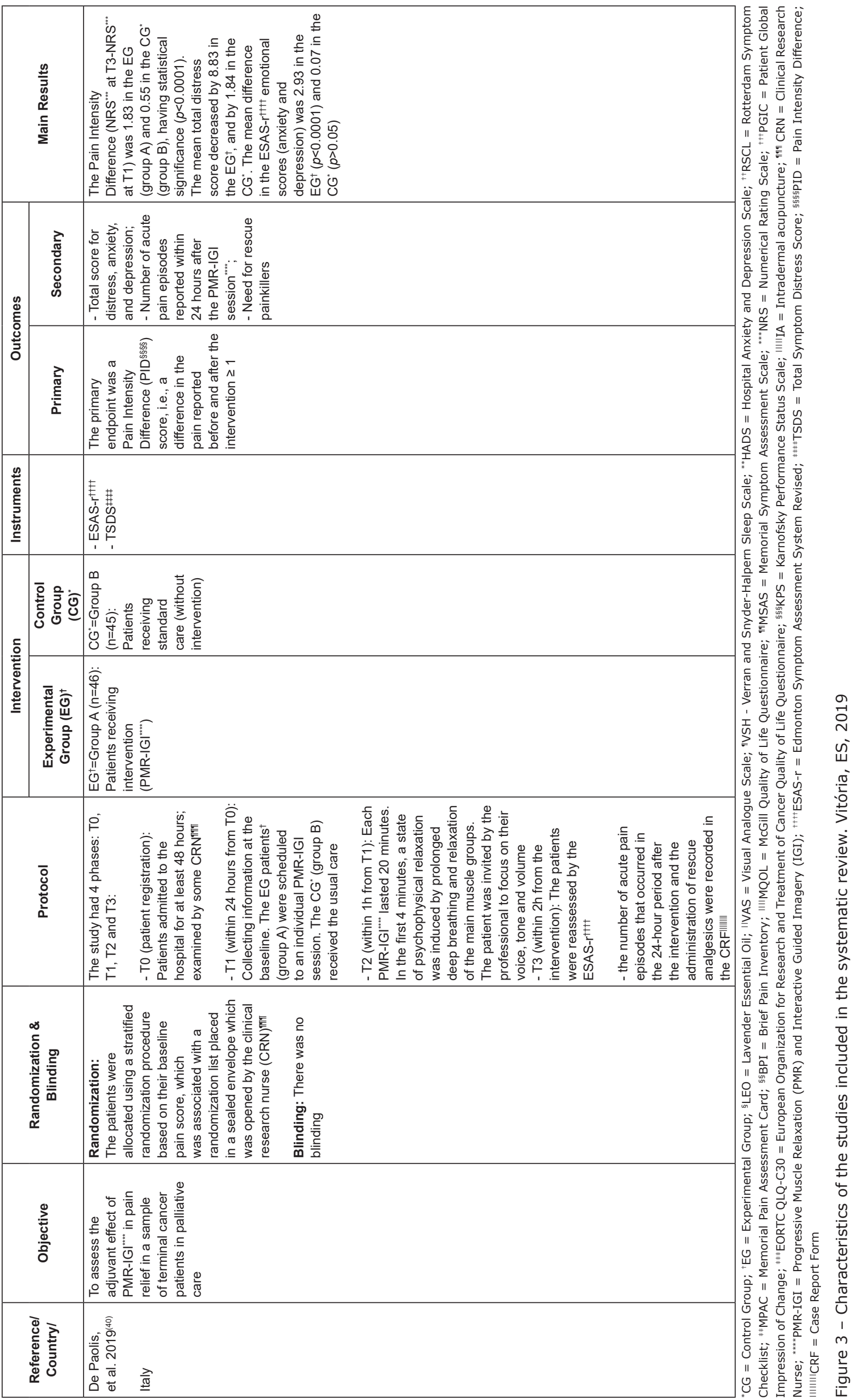


The total number of research participants among the included studies was 609 patients, with samples varying from 24 to 380 patients. Regarding the use of complementary therapies embraced in the included studies, it was verified that three studies used massage therapy ${ }^{(35-37)}$, one study used a combination of progressive muscle relaxation and guided imaging ${ }^{(40)}$; and another two studies ${ }^{(38-39)}$ evaluated the use of acupuncture for cancer pain management in adult patients with advanced cancer in palliative care.

Regarding the follow-up time, all the studies showed a short-term follow-up, with the protocols varying from a single day ${ }^{(36,40)}$; one week ${ }^{(38)}$; two weeks ${ }^{(37)}$, three weeks ${ }^{(39)}$, to a maximum of 4 weeks ${ }^{(35)}$.

With regards to the risk of bias in the studies to be selected and assessed by the Cochrane Collaboration Bias Risk tool, it was verified that, in most of them $(83 \%)$, the reliability of the results can be questioned, either because they present a risk of uncertain bias $(n=4 ; 67 \%)^{(35-38)}$ or for exhibiting a high risk of bias $(n=1 ; 17 \%)^{(40)}$. Only one study was classified as being at low risk for bias, with all the domains scored in this category (Figure 4).

$*$

\begin{tabular}{|c|c|c|c|c|c|c|c|c|}
\hline & $\begin{array}{l}\text { Allocation } \\
\text { of the } \\
\text { randomization } \\
\text { sequence } \\
\text { (selection bias) }\end{array}$ & $\begin{array}{l}\text { Allocation } \\
\text { concealment } \\
\text { (selection } \\
\text { bias) }\end{array}$ & $\begin{array}{l}\text { Blinding } \\
\text { of the } \\
\text { participants } \\
\text { and the team } \\
\text { involved } \\
\text { (performance } \\
\text { bias) }\end{array}$ & $\begin{array}{l}\text { Blinding of } \\
\text { outcome } \\
\text { evaluators } \\
\text { (detection } \\
\text { bias) }\end{array}$ & $\begin{array}{c}\text { Incomplete } \\
\text { outcomes } \\
\text { (attrition } \\
\text { bias) }\end{array}$ & $\begin{array}{c}\text { Report of } \\
\text { selective } \\
\text { outcome } \\
\text { (publication } \\
\text { bias) }\end{array}$ & $\begin{array}{l}\text { Other } \\
\text { sources } \\
\text { of bias }\end{array}$ & $\begin{array}{c}\text { Bias Risk } \\
\text { Classification }\end{array}$ \\
\hline Studies & \multicolumn{7}{|c|}{ Bias Risk Domain } & \\
\hline Soden, et al., $2004^{(35)}$ & $?$ & + & + & $?$ & + & + & + & Uncertain \\
\hline Kutner, et al., $2008^{(36)}$ & + & + & - & $?$ & + & + & + & Uncertain \\
\hline $\begin{array}{l}\text { Lopez-Sedin, et al., } \\
2012^{(37)}\end{array}$ & + & $?$ & & + & + & + & + & Uncertain \\
\hline Lam, et al., $2017^{(38)}$ & + & + & - & + & + & + & $?$ & Uncertain \\
\hline Kim; Lee, $2018^{(39)}$ & + & + & + & + & + & + & + & Low \\
\hline $\begin{array}{l}\text { De Paolis, et al., } \\
2019^{(40)}\end{array}$ & & + & & & + & + & $?$ & High \\
\hline
\end{tabular}

$+$

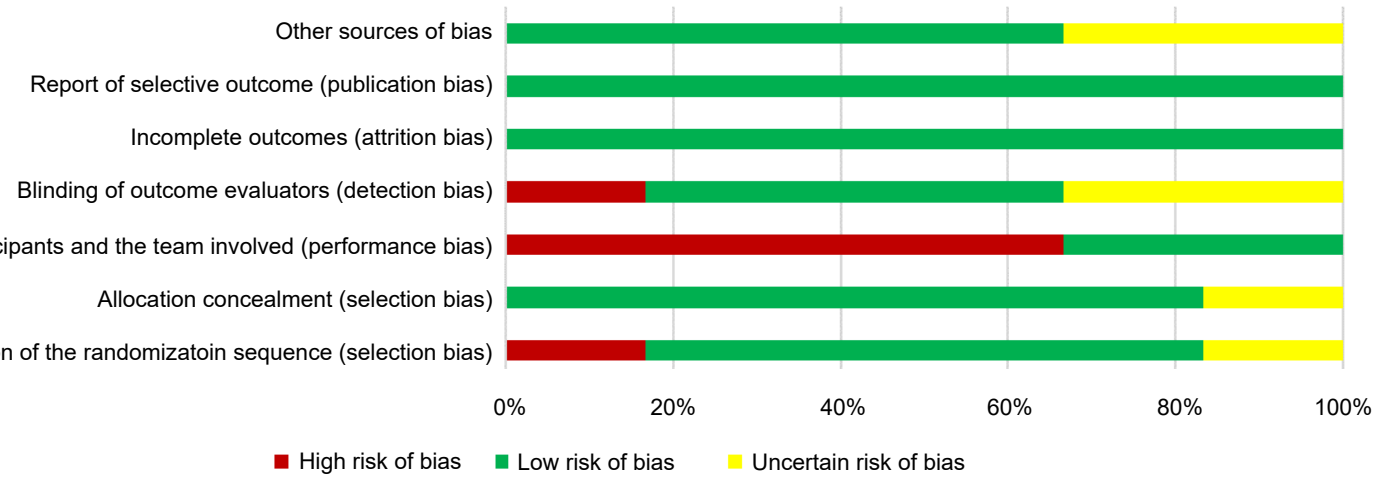

${ }^{*}$ Evaluation of the internal validity and of the risk of bias of the randomized controlled trials (RCTs) included in the study according to the Cochrane Collaboration Tool to assess the risk of bias in Randomized Controlled Trials; ${ }^{+}$Percentage of risk of bias among the RCTs by domains of the Cochrane Collaboration Tool to assess the risk of bias in Randomized Controlled Trials. The plus symbol (+) indicates low risk for bias; the minus symbol (-) indicates high risk for bias; the question mark (?) indicates uncertain risk for bias

Figure 4 - Risk for bias of the six studies included and evaluated by the Cochrane Collaboration tool(32). Vitória, ES, Brazil, 2019

We observed that four of the included studies(36-38,40), corresponding to $67 \%$ of the sample, displayed high risk for bias for the "blinding of the participants and the team involved" domain (performance bias). Two studies(35-36), corresponding to $33 \%$ of the sample, displayed an uncertain risk of bias for the "blinding of outcome evaluators" domain (detection bias), and another two other $(38,40)$ also exhibited an uncertain bias risk for the "other sources of bias" domain. It should be noted that all six studies were classified as low risk for bias for the "incomplete outcomes" and "report of selective outcomes" domains, representing low attrition and publication bias, respectively. 


\section{Discussion}

The clinical use and assessment of the potential benefits of the complementary therapies in the treatment of cancer patients has recently increased in both pediatric ${ }^{(18-22)}$ and adult patients ${ }^{(23-26)}$. Among the manipulation practices based on the body, the therapeutic massage stands out as the most commonly used complementary therapy modality ${ }^{(41-42)}$.

In this review, half of the included studies used massage therapy as $\mathrm{CT}^{(35-37)}$. Another study used a combination of progressive muscle relaxation and interactive guided imaging(40); and another two studies ${ }^{(38-39)}$ evaluated the use of acupuncture for the management of cancer pain in adult patients with advanced cancer in palliative care. Among the studies in this review that used massage therapy for the management of cancer pain in the study population, two demonstrated a beneficial effect ${ }^{(36-37)}$ and one study showed no statistically significant differences(35).

In summary, a study(36) suggested that the massage can be more effective than simple touch in reducing cancer pain and improving mood immediately after the treatment sessions. However, the sustained benefits of the massage in this population were less evident. Likewise, another study ${ }^{(37)}$ revealed that the combination of massage therapy and exercise showed to be effective in immediately reducing cancer pain, distress, and suffering, as well as improving mood in patients with terminal cancer.

Corroborating to the beneficial findings of the articles in the sample of our review, in other previous studies, the therapeutic massage has been shown to increase blood and lymphatic circulation, decrease inflammation and edema, relax muscles, increase dopamine and serotonin levels and also the number of lymphocytes ${ }^{(41-44)}$. In addition, randomized controlled trials have reported positive results from the massage therapy on the neuroendocrine and immune systems of women with early breast cancer, including reduced levels of anxiety, depression, anger, and fear, as well as increased levels of dopamine, serotonin, number of NK cells and lymphocytes. One of the mechanisms underlying for the stimulating effect on the immune system by the massage therapy probably results from the reduction of cortisol levels, which are inversely associated with the activity of NK cells, and from the increase in serotonin and dopamine levels, which lead to a reduction in cortisol release ${ }^{(44)}$.

Other research studies on massage therapy have also shown improvements in pain, nausea and other symptoms, immediately and over time ${ }^{(45-46)}$. The most consistent effect of massage has been to reduce the subjective degrees of anxiety, which can be more sensitive than the objective indicators for relaxation/ arousal(42). In addition, a number of qualitative studies corroborate this potential of the massage to promote relaxation and feelings of well-being ${ }^{(41,47)}$.

Additionally, a systematic review identified six RCTs related to the relaxing effects of aromatherapy massage. Three of these studies involved cancer patients and compared massage with and without the addition of essential oils. These studies suggest that aromatherapy massage may have a mild transient anxiolytic effect. However, there was no evidence of a sustained effect over time, and no beneficial effect on depression(48).

Contrary to the aforementioned findings, a study in our review found that adding lavender essential oil did not appear to increase the beneficial effects of the massage ${ }^{(35)}$. In line with this finding, there is a previous study that also did not detect statistically significant changes on cancer symptoms over time ${ }^{(49)}$. A recent systematic review pointed out that, when compared to ordinary massage alone, aromatherapy massage does not provide significant effectiveness in improving anxiety among cancer patients in palliative care ${ }^{(50)}$. It should be noted that one of the main limitations in examining the effectiveness of manual massage in cancer patients is the lack of standardization of its application (technique and dosage) and the difficulty of including a control group ${ }^{(51)}$.

In our review, the results of the study that evaluated the use of MR-IGI (progressive muscle relaxation and interactive guided image) was considered as an effective adjuvant in the relief of suffering related to cancer pain in these patients ${ }^{(40)}$. In line with this result is a randomized clinical trial that evaluated the effects of muscle relaxation and guided image in 80 women with breast cancer, before and after stress periods, specifically chemotherapy, radiotherapy, and surgery. The results revealed that the use of this complementary therapy modality changed important responses of the immune system, leading to an increase in the number of activated $T$ cells and in the NK cells' activity(52). A pilot RCT conducted with 40 hospitalized cancer patients who investigated the contribution of PMR + IGI to pain relief, found significant differences in pain intensity in $31 \%$ of the PMR + IGI group versus $8 \%$ in the control group(53).

As for the studies in our review that tested the use of acupuncture(38-39), they exhibited divergent results. While a study indicated that si guanxue acupuncture plus the commonly used acupuncture points (PC6; ST36; SP6) tends to be effective in reducing cancer pain(38), another study pointed out that, although the treatment with IA appeared to be viable and safe for patients with advanced cancer, it did not demonstrate significant differences in the groups (experimental and control) 
mainly due to the control group (Sham IA) limitation ${ }^{(39)}$. A recent randomized clinical trial of parallel arms conducted with 31 cancer patients who complained of pain greater than or equal to four on the Numerical Pain Scale, and aimed to evaluate the effectiveness of auricular acupuncture on cancer pain in patients undergoing chemotherapy treatment and possible changes in the consumption of analgesics after the application of the intervention, verified that, after the eight sessions of auricular acupuncture, there was a statistically significant difference between the groups in the reduction of pain intensity $(p<0.001)$, as well as in the consumption of medications $(p<0.05)$. The authors concluded that auricular acupuncture was effective in reducing cancer pain in patients undergoing chemotherapy ${ }^{(7)}$.

Moreover, a review of the literature reported diverse evidence that acupuncture improves the immune function through the modulation of the NK cells' activity. A hypothetical model has been proposed to explain how acupuncture stimulates the immune system by stimulating the ST36 acupoint. This point is known as the "immune boosting point", as it is able to improve the functioning of the immune system. The stimulation of this acupoint induces the release of nitric oxide, a neurotransmitter that stimulates, through sensory nerves, the lateral area of the hypothalamus, promoting the secretion of opioid peptides, such as $\beta$-endorphin. Through the bloodstream, this peptide reaches the spleen and other parts of the body, binding to the opioid receptors expressed on the surface of NK cells. When binding to the receptors, $\beta$-endorphin stimulates the NK cells to amplify the expression of cytotoxic molecules, tumoricidal activity and, consequently, the production of IFN-y. This cytokine induces the expression of NK cell receptors and possibly the secretion of cytokines by other cells of the immune system, orchestrating and amplifying anti-cancer immune responses(54).

Acupuncture is one of the most popular forms of complementary medicine ${ }^{(29,55)}$ and its use is mainly linked to improving the psychological symptoms through sympathomimetic pathways ${ }^{(56)}$. Traditional Chinese Acupuncture (TCA) is used as a complement to the conventional treatment for several pathological conditions and its focus is to relieve symptoms by reorganizing the body's energy, aiming at leading to selfhealing(55). Sham Acupuncture (SA), also called placebo, can be understood as an intervention performed in a false way, as it is performed outside the points established by the $\operatorname{TCA}^{(57)}$. The scarcity of research studies with acceptable controls that actually mimic all aspects of the tested intervention has been the main methodological problem presented by the studies that use acupuncture as a therapy ${ }^{(29,57)}$.

This systematic review has some limitations. When evaluated methodologically by the Cochrane Collaboration tool, most of the included studies displayed a risk for uncertain bias $(n=4 ; 67 \%)$, leading to questions about the reliability of the results, thus compromising the external validity of these studies. Another important limitation concerns the fact that different interventions are being evaluated in different types of cancer, making the studies heterogeneous and, for this reason, quantitative assessments were not feasible. In addition, the short follow-up time (follow-up in a single day and up to a maximum of four weeks) may have impaired the measurement of some outcomes. To this end, it is suggested that new RCTs be conducted with a longer follow-up, to detect whether the effects of using complementary therapies for cancer pain management in these patients are sustained in the medium and long term. Thus, there is a need for further RCTs with representative samples of the population and with low risk for bias.

\section{Conclusion}

The evidence from these six RCTs, mainly in three studies that evaluated the use of the massage therapy for cancer pain management in adults with cancer in palliative care, showed to be effective and promising for pain reduction. However, although the three studies that addressed massage therapies have positive results and the qualitative analysis of the review suggests the benefit of this practice in reducing cancer pain, the need for further studies with representative samples and rigorous methodological designs is highlighted in order to confirm such findings, since the three studies were evaluated with uncertain bias risk. Due to the fact that they exhibit opposite results, the two studies that evaluated the use of acupuncture as a complementary therapy were insufficient to accurately assert the efficacy of such therapy on the reduction of cancer pain, mainly because they differ on the methodological aspects (type of acupuncture, application techniques, and evaluated acupuncture points), therefore needing to get more evidence to elucidate such findings. 


\section{References}

1. Bray F, Ferlay J, Soerjomataram I, Siegel RL, Torre LA, Jemal A. Global cancer statistics 2018: GLOBOCAN estimates of incidence and mortality worldwide for 36 cancers in 185 countries. CA Cancer J Clin. 2018 Nov 20;68(6):394-424. doi: 10.3322/caac.21492

2. Siegel RL, Miller KD, Jemal A. Cancer statistics, 2020. CA Cancer J Clin. 2020 Jan 22;69(1):7-34. doi: $10.3322 /$ caac. 21590

3. World Health Organization. Cancer - World Health Organization. [Internet]. 2020 [cited Abr 15, 2020]. Available from: https://www.who.int/cancer/en/

4. Instituto Nacional de Câncer José Alencar Gomes da Silva (BR). Coordenação de Prevenção e Vigilância. Estimativa 2020: incidência de câncer no Brasil. [Internet]. 2019. [cited Apr 24, 2020]. Available from: https://www.inca.gov.br/sites/ufu.sti.inca.local/files/ media/document/estimativa-2020-incidencia-decancer-no-brasil.pdf

5. Garcia TR. Classificação Internacional para a Prática de Enfermagem - CIPE $^{\circledR}$ Versão 2017. Porto Alegre: Artmed; 2018.

6. Forbes K. Pain in patients with cancer: the World Health Organization analgesic ladder and beyond. Clin Oncol. 2011;23(6):379-80. doi: 10.1016/j.clon.2011.04.016

7. Ruela LO, Iunes DH, Nogueira DA, Stefanello J, Gradim CVC. Effectiveness of auricular acupuncture in the treatment of cancer pain: randomized clinical trial. Rev Esc Enferm USP. 2018 Dec 13;52:e03402. doi: 10.1590/S1980-220X2017040503402

8. Fallon M, Giusti R, Aielli F, Hoskin P, Rolke R, Sharma M, et al. Management of cancer pain in adult patients: ESMO Clinical Practice Guidelines. Ann Oncol. 2018;29(Suppl4):iv166-iv191. doi: http://dx.doi. org/10.1093/annonc/mdy152

9. Mercadante S. The Patient with Difficult Cancer Pain. Cancer. 2019 Apr 19;11(4):565. doi: 10.3390/ cancers 11040565

10. Dalal S, Bruera E. End-of-life care matters: palliative cancer care results in better care and lower costs. Oncologist. 2017 Mar 17; 22(4):361-8. doi: 10.1634/ theoncologist.2016-0277

11. Deng G. Integrative medicine therapies for pain management in cancer patients. Cancer J. 2019;25(5): 343-8. doi: 10.1097/PPO.0000000000000399

12. World Health Organization. National cancer control programmes: polices and managerial guidelines. [Internet]. $2^{\text {nd }}$ ed. Geneva: WHO; 2002. [cited Oct 20,
2019] Available from: https://www.who.int/cancer/ media/en/408.pdf

13. Freire MEM, Costa SFG, Lima RAG, Sawada NO. Healthrelated quality of life of patients with cancer in palliative care. Texto Contexto Enferm. 2018;27(2):e5420016. doi: 10.1590/0104-070720180005420016

14. Mendes TR, Boaventura RP, Castro MC, Mendonça MAO. Occurrence of pain in cancer patients in palliative care. Acta Paul Enferm. 2014;27(4):356-61. 10.1590/1982-0194201400059

15. Lopes-Júnior LC, Olson K, Omena Bomfim E, Pereirada-Silva G, Nascimento LC, Lima RA. Translational research and symptom management in oncology nursing. $\mathrm{Br}$ J Nurs. 2016;25(10). doi: 10.12968/bjon.2016.25.10.S12

16. Abrahão CA, Bomfim E, Lopes-Junior LC, Pereira-da-Silva G. Complementary therapies as a strategy to reduce stress and stimulate the immunity of women with breast cancer. J Evid Based Integr Med. 2019 Mar 27;24:2515690X19834169. doi: $10.1177 / 2515690 \times 19834169$

17. National Centre for Complementary and Alternative Medicine. Complementary, Alternative, or Integrative Health: What's in a Name? [Internet]. 2019 [cited Sep 20, 2019]. Available from: http://nccam.nih.gov/ health/whatiscam

18. Lopes-Júnior LC, Bomfim EO, Nascimento LC, Nunes MDR, Pereira-da-silva G, Lima RAG. Nonpharmacological interventions to manage fatigue and psychological stress in children and adolescents with cancer: an integrative review. Eur J Cancer Care (Engl). 2016 Nov 10;25(6):921-35. doi: 10.1111/ecc.12381

19. Lopes-Júnior LC, Pereira-da-Silva G, Silveira DSC, Veronez LC, Santos JC, Alonso JB, et al. The effect of clown intervention on self-report and biomarker measures of stress and fatigue in pediatric osteosarcoma inpatients: a pilot study. Integr Cancer Ther. 2018 Sep 10;17(3):928-940. doi: 10.1177/1534735418781725 20. Lopes-Júnior LC, Silveira DSC, Olson K, Bomfim EO, Veronez LC, Santos JC, et al. Clown intervention on psychological stress and fatigue in pediatric patients with cancer undergoing chemotherapy. Cancer Nurs. 2019 Feb 12;42. doi: 10.1097/NCC.0000000000000690.

21. Nunes MDR, Jacob E, Bomfim EO, Lopes-Junior $\mathrm{CL}$, De Lima RAG, Floria-Santos $\mathrm{M}$, et al. Fatigue and health related quality of life in children and adolescents with cancer. Eur J Oncol Nurs. 2017 Aug 8;29:39-46. doi: 10.1016/j.ejon.2017.05.001

22. Xavier WS, Pacheco STA, Silva LF, Nascimento LC, Lopes-Junior LC, Araújo BBM, et al. Nunes MDR. 
Nonpharmacological interventions in the improvement of quality of life in children and adolescent cancer patients. Acta Paul Enferm. 2020;33:e-APE-20190022. 10.37689/acta-ape/2020AR0022

23. Rhee TG, Pawloski PA, Parsons HM. Health-related quality of life among US adults with cancer: potential roles of complementary and alternative medicine for health promotion and well-being. Psychooncology. 2019 Feb 25;28(4):896-902. doi: 10.1002/pon.5039

24. Kuo YH, Tsaysh SH, Chang CC, Lia YC, Tung HH. Cancer impact, complementary/alternative medicine beliefs, and quality of life in cancer patients. J Altern Complement Med. 2018 Mar 29;24(3):276-81. doi: 10.1089/acm.2016.0396 25. Abuelgasim KA, Alsharhan Y, Alenzi T, Alhazzani A, Ali $Y Z$, Jazieh AR. The use of complementary and alternative medicine by patients with cancer: a cross-sectional survey in Saudi Arabia. BMC Complement Altern Med. 2018 Mar 12;18(1):88. doi: 10.1186/s12906-018-2150-8

26. Wode K, Henriksson R, Sharp L, Stoltenberg A, Hök Nordberg J. Cancer patients' use of complementary and alternative medicine in Sweden: a cross-sectional study. BMC Complement Altern Med. 2019 Mar 13;19(1):62. doi: http://dx.doi.org/10.1186/s12906-019-2452-5

27. Methley AM, Campbell S, Chew-Graham C, McNally R, Cheraghi-Sohi S. PICO, PICOS and SPIDER. A comparison study of specificity and sensitivity in three search tools for qualitative systematic reviews. BMC Health Serv Res. 2014 Nov 21;14:579. doi: 10.1186/s12913-014-0579-0 28. Melnyk BM, Fineout-Overholt E. Evidence-based practice in nursing \& healthcare. A guide to best practice. $2^{\text {nd }}$ ed. Philadelphia; 2011.

29. Lopes-Júnior CL, Cruz LA, Leopoldo VC, Campos FR, Almeida AM, Silveira RCC. Effectiveness of traditional Chinese acupuncture versus sham acupuncture: a systematic review. Rev. Latino-Am. Enfermagem. 2016 Aug 15;24:e2762. doi: 10.1590/1518-8345.0647.2762 30. Gonçalves CA, Lopes-Júnior LC, Nampo FK, Zilly A, Mayer PCM, Pereira-da-Silva G. Safety, efficacy and immunogenicity of therapeutic vaccines in the treatment of patients with high-grade cervical intraepithelial neoplasia associated with human papillomavirus: a systematic review protocol. BMJ Open. 2019 Jul 17;9(7):e026975. doi: 10.1136/bmjopen-2018-026975 31. Lopes-Júnior LC, Lima RAG, Olson K, Bomfim E, Neves ET, Silveira DSC, et al. Systematic review protocol examining the effectiveness of hospital clowns for symptom cluster management in pediatrics. BMJ Open. 2019 Jan 21;9(1):e026524. doi: 10.1136/ bmjopen-2018-026524
32. Higgins JPT, Green S. Cochrane Handbook for Systematic Reviews of Interventions. Version 5.1.0. [Internet]. London: The Cochrane Collaboration; 2016. [cited Sep 20, 2019] Available from: https://training. cochrane.org/handbook

33. Laurant M, van der Biezen M, Wijers N, Watananirun K, Kontopantelis E, van Vught AJ. Nurses as substitutes for doctors in primary care. Cochrane Database Syst Rev. 2018 Jul 16;7:CD001271. doi: 10.1002/14651858. CD001271.pub3

34. Moher D, Liberati A, Tetzlaff J, Altman DG, PRISMA Group. Preferred reporting items for systematic reviews and meta-analyses: the PRISMA statement. PLoS Med. 2009 Jul 21;6(7):e1000097. doi: 10.1371/journal.pmed.1000097 35. Soden K, Vicent K, Craske S, Lucas C, Asheley S. A randomized controlled trial of aromatherapy massage in a hospice setting. Palliat Med. 2004 Mar 10;18(2):87-92. doi: 10.1191/0269216304pm874oa

36. Kurtner JS, Smith MC, Corbin L, Hemphill L, Benton $\mathrm{K}$, Mellis BK, et al. Massage therapy versus simple touch to improve pain and mood in patients with advanced cancer: a randomized trial. Ann Intern Med. 2008 Sep 16;149(6):369-79. doi: 10.7326/0003-4819-149-6200809160-00003

37. López-Sendín N, Alburquerque-Sendín F, Cleland JA, Fernández-de-las-Peñas $C$. Effects of physical therapy on pain and mood in patients with terminal cancer: a pilot randomized clinical trial. J Altern Complement Med. 2012 May 10;18(5):480-6. doi: 10.1089/acm.2011.0277

38. Lam TY, Lu LM, Ling WM, Lin LZ. A pilot randomized controlled trial of acupuncture at the Si Guan Xue for cancer pain. BMC Complement Altern Med. 2017 Jun 26;17(1):335. doi: 10.1186/s12906-017-1838-5

39. Kim K, Lee S. Intradermal acupuncture along with analgesics for pain control in advanced cancer cases: a pilot, randomized, patient-assessor-blinded, controlled trial. Integr Cancer Ther. 2018 Dec 7;17(4):1137-43. doi: $10.1177 / 1534735418786797$

40. De Paolis G, Naccarato A, Cibelli F, D'Alete A, Mastroianni $C$, Surdo $L$, et al. The effectiveness of progressive muscle relaxation and interactive guided imagery as a pain-reducing intervention in advanced cancer patients: a multicenter randomized controlled non- pharmacological trial. Complement Ther Clin Pract. 2019 Feb 2;34:280-7. doi: 10.1016/j.ctcp.2018.12.014 41. Ho SSM, Kwong ANL, Wan KWS, Ho RML, Chow KM. Experiences of aromatherapy massage among adult female cancer patients: a qualitative study. J Clin Nurs. 2017;26(23-24):4519-4526. doi:10.1111/jocn.13784 
42. Lee SH, Kim JY, Yeo S, Kim SH, Lim S. Meta-analysis of massage therapy on cancer pain. Integr Cancer Ther. 2015;14(4):297-304. doi: 10.1177/1534735415572885 43. Hernandez-Reif M, Field T, Ironson G, Beutler J, Vera $Y$, Hurley J, et al. Natural killer cells and lymphocytes increase in women with breast cancer following massagetherapy. Int J Neurosci. 2005 Apr 10;115: 495-510.doi: 10.1080/00207450590523080

44. Chandwani KD, Ryan JL, Peppone LJ, Janelsins MM, Sprod LK, Devine K, et al. Cancer-related stress and complementary and alternative medicine: a review. Evid Based Complement Alternat Med. 2012;2012:979213. doi: $10.1155 / 2012 / 979213$

45. Cassileth BR, Vickers AJ. Massage therapy for symptom control: outcome study at a major cancer center. J Pain Symptom Manage. 2004 Sep 8;28(3):244-9. doi: 10.1016/j.jpainsymman.2003.12.016

46. Billhult A, Stener-Victorin E, Bergbom I. The experience of massage during chemotherapy treatment in breast cancer patients. Clin Nurs Res. 2007 May 3;16(2):85-99. doi: 10.1177/1054773806298488

47. Billhut A, Dahlberg L. A meaning relief from suffering: Experience of massage in cancer care. Cancer Nurs. [Internet] 2001 Jun 3 [cited Feb 2, 2020];24(3):180-4. Available from: https://insights. ovid.com/pubmed?pmid=11409061

48. Shin ES, Seo KH, Lee SH, et al. Massage with or without aromatherapy for symptom relief in people with cancer. Cochrane Database Syst Rev. 2016 Jun 3;(6):CD009873. doi: 10.1002/14651858.CD009873.pub3 49. Wilkie DJ, Kampbell J, Cutshall S, Halabisky H, Harmon $\mathrm{H}$, Johnson LP, et al. Effects of massage therapy on pain intensity, analgesics and quality of life in patients with cancer pain: a pilot study of a randomized controlled trial conducted within hospice care delivery. Hosp J. 2000;15(3):31-53.

50. Hsu CH, Chi CC, Chen PS, Wang SH, Tung TH, Wu SC. The effects of aromatherapy massage on improvement of anxiety among patients receiving palliative care: A systematic review of randomized controlled trials. Medicine (Baltimore). 2019;98(9):e14720. doi: 10.1097/ MD.0000000000014720

51. Smith M, Kutner J, Hemphill L, Yamashita T, Felton S. Developing control and treatment conditions

Corresponding author:

Luís Carlos Lopes-Júnior

E-mail: lopesjr.lc@gmail.com

(iD) https://orcid.org/0000-0002-2424-6510 in a clinical trial of massage therapy for advanced cancer. J Soc Integr Oncol. 2007 Fall;5(4):139-46. doi: $10.2310 / 7200.2007 .014$

52. Eremin O, Walker MB, Simpson E, Heys SD, Ah-See $A K$, Hutcheon AW, et al. Immuno-modulatory effects of relaxation training and guided imagery in women with locally advanced breast cancer undergoing multimodality therapy: a randomised controlled trial. Breast 2009. Feb 4;18(1):17-25. doi: 10.1016/j.breast.2008.09.002 53. Kwekkeboom KL, Abbott-Anderson K, Cherwin C, Roiland R, Serlin RC, Ward SE. Pilot randomized controlled trial of a patient-controlled cognitivebehavioral intervention for the pain, fatigue, and sleep disturbance symptom cluster in cancer. J Pain Symptom Manage. 2012 Jul 7;44(6):810-22. doi: 10.1016/j. jpainsymman.2011.12.281

54. Johnston MF, Ortiz Sánchez E, Vujanovic NL, Li W. Acupuncture may stimulate anticancer immunity via activation of natural killer cells. Evid-Based Complement Alternat Med. 2011;3(10):1-14. doi: 10.1093/ecam/nep236 55. Baviera, AF, Olson K., Paula JMD, Toneti, BF, Sawada, NO. Acupuncture in adults with ChemotherapyInduced Peripheral Neuropathy: a systematic review. Rev. Latino-Am. Enfermagem. 2019 Mar 10;27:e3126. doi: $10.1590 / 1518-8345.2959 .3126$

56. Uchida S, Hotta H. Acupuncture affects regional blood flow in various organs. Evid Based Complement Alternat Med. 2008 Jun 8;5(2):145-51. doi: 10.1093/ ecam/nem051

57. Kreiner M, Zaffaroni A, Alvarez R, Clark G. Validation of a simplified sham acupuncture technique for its use in clinical research: a randomized, single blind, crossover study. Acupunct Med. 2010 Mar 4;28(1):33-6. doi: 10.1136/aim.2009.001735

Received: Feb 21 ${ }^{\text {st }} 2020$ Accepted: Jun $24^{\text {th }} 2020$

Associate editor: Maria Lúcia Zanetti

Copyright $\odot \mathbf{2 0 2 0}$ Revista Latino-Americana de Enfermagem This is an Open Access article distributed under the terms of the Creative Commons (CC BY).

This license lets others distribute, remix, tweak, and build upon your work, even commercially, as long as they credit you for the original creation. This is the most accommodating of licenses offered. Recommended for maximum dissemination and use of licensed materials. 